\title{
An Adenovirus Vector Containing the Suicide Gene Thymidine Kinase for a Broad Application in Cancer Gene Therapy
}

\author{
GS Magalhães, AR Muotri, MCN Marchetto, CFM Menck, AM Ventura ${ }^{+}$
}

Departamento de Microbiologia, Instituto de Ciências Biomédicas, Universidade de São Paulo, Av. Prof. Lineu Prestes 1374 , 05508-900 São Paulo, SP, Brasil

Treatment of cancer using gene therapy is based on adding a property to the cell leading to its elimination. One possibility is the use of suicide genes that code for enzymes that transform a pro-drug into a cytotoxic product. The most extensively used is the herpes simplex virus thymidine kinase (TK) gene, followed by administration of the antiviral drug ganciclovir $(G C V)$. The choice of the promoter to drive the transcription of a transgene is one of the determinants of a given transfer vector usefulness, as different promoters show different efficiencies depending on the target cell type. In the experiments presented here, we report the construction of a recombinant adenovirus carrying TK gene (Ad-TK) driven by three strong promoters $\left(P_{C M V I E}\right.$, SV40 and EN1) and its effectiveness in two cell types. Human HeLa and mouse CCR2 tumor cells were transduced with Ad-TK and efficiently killed after addition of GCV. We could detect two sizes of transcripts of TK gene, one derived from the close together $P_{C M V I E}$ $S V 40$ promoters and the other from the $1.5 \mathrm{~Kb}$ downstream EN1 promoter. The relative amounts of these transcripts were different in each cell type thus indicating a higher flexibility of this system.

Key words: ganciclovir - adenovirus - thymidine kinase - cancer - gene therapy

Insertion of genes that activate pro-drugs to produce cytotoxity in tumor cells, is considered a potential therapeutic strategy for cancer treatment. One specific cytotoxic gene therapy approach is viral transduction of the herpes simplex virus (HSV)-thymidine kinase (TK) gene, followed by treatment with the antiviral drug, ganciclovir (GCV) (Moolten 1986). GCV is a good substrate for viral TK, but is not recognized by the mammalian analogous enzyme (Ellion et al. 1977). Viral TK phosphorylates GCV to the monophosphate form, which is then converted to the triphosphate form by cytoplasmic enzymes. GCV triphosphate, when incorporated into replicating DNA, stops chain elongation and results in cell death. In addition, GCV treatment exerts a bystander effect, as it causes also the death of the neighboring untransduced cells (Ezzeddine et al. 1991, Freeman et al. 1993, Samejima \& Meruelo 1995).

For several reasons such as stability of the particle and broad range of target cells, adenoviruses are attracting increasing attention as expression vectors, especially for human gene therapy (Berkner 1992). The adenovirus vectors that have been used for this purpose carry the transgenes replacing the E1 region from their genome, since its deletion renders the viruses defective for replication and incapable of producing infectious viral particles in target cells. These vectors are able to grow only in HEK 293 cells, which supply E1 products in trans (Graham et al. 1977). Adenovirus vectors with the TK gene have been used extensively in a variety of tumor cells in

This work was supported by Fapesp and CNPq.

${ }^{+}$Corresponding author. Fax: +55-11-3091.7354. E-mail: amventur@icb.usp.br

Received 5 July 2001

Accepted 6 February 2002 vitro and in vivo (Chen et al. 1994, Su et al. 1997, Sterman et al. 1998, Herman et al. 1999, Trask et al. 2000). Since it has been reported that the cell type affects the transcription from a given promoter (Everett 1988, Shillitoe \& Noonan 2000), different promoters should be considered when an efficient expression has to be achieved.

Differently from the previous adenovirus vectors that have only one promoter (Chen et al. 1994, Rosenfeld et al. 1995, Park et al. 1997, Anderson et al. 1999), we report here the construction of an adenoviral vector harboring three different strong promoters to drive TK gene expression: the human cytomegalovirus immediate early promoter $\left(\mathrm{P}_{\mathrm{CMV} \text { IE }}\right)$, the SV40 early promoter and the EN1 promoter (Ventura et al. 1990, Ventura \& Villa 1993). This Ad-TK was tested in two distinct tumor cell lines, human HeLa and the mouse CCR2. This is an effort to improve the efficiency of TK gene expression regardless of the tumor cell target since when one promoter is weak, one of the others could properly drive the transcription of TK gene to achieve a better level of expression.

\section{MATERIALS AND METHODS}

Cell lines, medium, and viruses - HeLa and HEK 293 cells (Graham et al. 1977) were purchased from the American Type Culture Collection, and CCR2 (NIH3T3 transformed by EJras) was described previously (Jasiulionis et al. 1996). HEK 293 cells were grown in Minimum Essential Medium (MEM, Life Technologies, Inc., USA), HeLa and CCR 2 cells in Dulbecco's Modified Eagle's Medium (DMEM, Life Technologies, Inc., USA), both supplemented with $10 \%$ fetal calf serum (Cultilab, Brazil) and gentamicin $(400 \mu \mathrm{g} / \mathrm{ml})$. The cells were maintained at $37^{\circ} \mathrm{C}$ in a $5 \% \mathrm{CO}_{2}$ atmosphere. As a control, a recombinant adenoviral vector encoding the Escherichia coli $\beta$-galactosidase gene under the control of cytomegalovirus promoter/enhancer (Ad- $\beta$ gal) was utilized (obtained from Généthon III - Service Assurance Qualité, France). 
Enzymes and primers - Restriction endonucleases (except PI-SceI and I-CeuI which were provided together with Adeno- $\mathrm{X}^{\mathrm{TM}}$ Expression System-Clontech, USA), T4 DNA ligase, Taq DNA polymerase, and proteinase $\mathrm{K}$ were from either New England Biolabs or Boehringer Mannheim (USA). The TK gene forward (F), reverse (R) and internal primers (synthesized by Life Technologies, Brazil) were drawn based on sequence data obtained by McKnight (1980). Their sequences and respective positions according to that data are presented below.

TKF-5'TATGGCTTCGTACCCCGGCC3' (308-328)

TKR - 5' CTCCTTCCGTGTTTCAGTTAGC3' (1432-1453)

TKR1 - 5'CCATTGTTATCTGGGCGC3' (676-694)

TKR2 - 5'CAGGTCCAGCCGCTCG3' (980-996)

TKR3 - 5'TGCATGGAACGGAGGCG3' (1261-1287)

TKF1 - 5'TGGGGGCTTCCGAGAC3' (580-596)

TKF2 - 5'TGGCCCTCATCCCGCC3' (880-896)

Plasmids construction - TK gene was amplified via PCR from the plasmid pMC19TK kindly provided by Dr Mario Capechi (Mansour et al. 1988) with the primers TKF and TKR. Amplification was performed during 30 cycles of $94^{\circ} \mathrm{C}(1 \mathrm{~min}), 57^{\circ} \mathrm{C}(1 \mathrm{~min})$ and $72^{\circ} \mathrm{C}(1 \mathrm{~min} 30 \mathrm{sec})$, after an initial $5 \mathrm{~min}$ at $94^{\circ} \mathrm{C}$ to denature input DNA, with a final $5 \mathrm{~min}$ at $72^{\circ} \mathrm{C}$ for strand extension. The $1200 \mathrm{bp}$ product was purified and cloned into the $E c o R V$ site of pSH plasmid (Ventura \& Villa 1993) that contains SV40 and EN1 promoters, generating pSHTK. TK gene sequence was confirmed, after cloning, by automatic sequencing with the ABI prism® Big Dye Terminator Cycle Sequencing Ready Reaction (Applied Biosystems, USA) using the primers described above (TKF, TKR, TKR1, TKR2, TKR3, TKF1, TKF2 and TKF3) and ABI PRISM ${ }^{\text {TM }} 310$ Genetic Analyzer (Applied Biosystems, USA). No mismatch by the PCR cloning was observed in the TK gene.

The insertion of the TK gene, SV40 and EN1 promoters in pShuttle (Clontech Inc., USA) was done with an intermediate vector, $\mathrm{pBI}-\mathrm{TK}$, constructed by sub-cloning TK gene and the two promoters (XhoI-NotI fragment) into pBI-L (Clontech Inc., USA). In this construct, XbaI sites flank the cassette. XbaI digested pBI-TK was used to transfer TK and promoters to pShuttle, resulting in the vector pShuttleTK. In this construct, TK gene is under the control of three promoters $\left(\mathrm{P}_{\mathrm{CMV}}\right.$ IE, $\mathrm{SV} 40$ early and EN1).

Characterization of pSHTK clones - CCR 2 cells were co-transfected with both pSHTK $(10 \mu \mathrm{g})$ and pSV40-neo $(1 \mu \mathrm{g})$ using Lipofectin (Life Technologies, Inc., USA) according to manufacturer's instructions. After $48 \mathrm{~h}$ the cells were treated with $400 \mu \mathrm{g} / \mathrm{ml}$ of Geneticin (Life Technologies, Inc., USA) in growth media to select the clones. The clones obtained were incubated in growth media containing different concentrations $(12.5,25$ and $50 \mu \mathrm{g} /$ $\mathrm{ml}$ ) of GCV. DNA from the sensitive clones was extracted and submitted to PCR as described previously. RNA was extracted according to the acid guanidinium thiocyanatephenol-cloroform method (Chomczynski \& Sacchi 1987) and Northern blot (Sambrook et al. 1989) was performed using Hybond $\mathrm{N}^{+}$nylon membranes (Amersham, USA), and hybridized with a $\left[{ }^{32} \mathrm{P}\right]$ labeled probe of $1200 \mathrm{bp}$ generated by PCR of pSHTK using the TKF and TKR primers.
Generation of recombinant adenoviral plasmid - Recombinant adenovirus vector expressing TK downstream of three promoters (SV40, EN1 and $\mathrm{P}_{\mathrm{CMV} \text { IE }}$ ) was constructed using the Adeno- $\mathrm{X}^{\mathrm{TM}}$ Expression System (Clontech Inc., USA), following manufacturer's instructions, which exploits the ligation method (Mizuguchi \& Kay 1998). Briefly, the pShuttle-TK was digested with PISceI and I-CeuI to release the expression cassette containing the three promoters (SV40, EN1 and $\mathrm{P}_{\mathrm{CMV} \text { IE) }}$, TK gene and the bovine growth hormone polyadenylation signal (BGA poly A). This DNA fragment was subsequently ligated to the $\mathrm{pAdeno-X}$, digested with the same enzymes to generate pAdeno-XTK. After ligation it was digested with Swa I restriction enzyme to avoid the occurrence of non-recombinant plasmids and used to transform $E$. coli $\mathrm{DH} 5-\alpha$, clones bearing ampicilin resistance were selected. Plasmids obtained were screened by digestion with the restriction enzymes Xho I, EcoR I and Xba I.

Ad-TK production - Approximately $10^{6}$ HEK 293 cells were plated in $25 \mathrm{~cm}^{2}$ flasks $24 \mathrm{~h}$ before transfection, by which time they reached $60-70 \%$ confluency. After that, $2.5 \mu \mathrm{g}$ of pAdeno-XTK, digested with PacI, were transfected using the calcium phosphate co-precipitation technique (CalPhos ${ }^{\mathrm{TM}}$ Mammalian Transfection kit, Clontech Inc., USA) according to the manufacturer's instructions. Upon evidence of extensive cytopathic effect the cells were harvested, submitted to three freeze and thawing cycles and centrifuged at 2,000Xg for $10 \mathrm{~min}$. The supernatant was collected and viral titer determined by plaque assay in HEK 293 cells. The presence of TK gene was accessed by Southern blot (Sambrook et al. 1989). Viral DNA was isolated (Hitt et al. 1998) and digested with XbaI, separated on a $0.8 \%$ agarose gel, transferred onto a Hybond $\mathrm{N}^{+}$nylon membrane (Amersham, USA) and hybridized with a $\left.{ }^{32} \mathrm{P}\right]$ labeled probe of $680 \mathrm{bp}$ generated by PCR from $\mathrm{pSHTK}$ using the TKF1 and TKR3 primers.

Adenovirus infection and ganciclovir treatment $\mathrm{HeLa}$ and CCR 2 cells were plated $24 \mathrm{~h}$ prior to infection, with all experiments being performed when cells reached a confluency of $70-80 \%$. The infection procedures were carried out with the recombinant adenoviruses (Ad-TK and Ad- $\beta$ gal) diluted in DMEM without serum and antibiotics for $1 \mathrm{~h}$ at $37^{\circ} \mathrm{C}$. Complete growth media containing GCV $(25 \mu \mathrm{g} / \mathrm{ml})$ was then added to the cell culture. After 4 days the cells were fixed and stained.

Analysis of TK gene transcripts after tranduction with Ad-TK - Hela and CCR2 cells $\left(10^{6}\right.$ cells in $75 \mathrm{~cm}^{2}$ flasks) were infected with $2 \mathrm{pfu} / \mathrm{cell}$ of Ad-TK. After $48 \mathrm{~h}$ RNA was extracted and a Northern blot performed as described above, with a [ $\left.{ }^{32} \mathrm{P}\right]$ labeled probe of $680 \mathrm{bp}$ generated by PCR from pSHTK using the TKF1 and TKR3 primers. Quantification of the probe radioactivity hybridized in the TK transcripts was done by exposition of the bloted Nylon membrane in a PhosphorImager Storm 840 (Molecular Dynamics, USA).

\section{RESULTS}

TK gene expression from $\mathrm{pSHTK}$ - Prior to the construction of Ad-TK it was necessary to verify if the subcloned TK gene sequence was correct and the expressed 
gene working properly. The vector pSHTK, constructed as described in Materials and Methods, has the TK gene driven by the EN1 and SV40 promoters. pSHTK and pSV40neo (which carries a eucariotic resistance marker) were co-transfected into CCR2 and clones were selected with geneticin (see Materials and Methods). All clones obtained were submitted to ganciclovir treatment and among them two showed sensitivity. The best GCV concentration was $25 \mu \mathrm{g} / \mathrm{ml}$, which did not show any apparent toxic effect to the control cells and was effective to kill cells harboring TK gene (data not shown). The presence and expression of TK gene in the GCV sensitive clones was also assessed by PCR and northern blot respectively (data not shown).

Construction of pAdeno-XTK vector - The overall strategy developed here is diagrammed in Fig. 1 and involves three steps. To begin with, the TK gene and promoters SV40 and EN1 were transferred from pSHTK to pBI-TK, and then to pShuttle vector, which contains the human cytomegalovirus immediate early promoter $\left(\mathrm{P}_{\mathrm{CMV}}\right.$ ${ }_{\mathrm{IE}}$ ), in such a way that the TK gene was placed downstream of the three promoters (see Materials and Methods). Next, the entire expression cassette, which in pShuttleTK is flanked by unique PI-SceI and I-CeuI sites, was excised using these enzymes and ligated into the pAdeno- $X$ vector digested with the same enzymes. The new vector contains a different resistance marker (ampicilin) from pShuttleTK (kanamycin), preventing

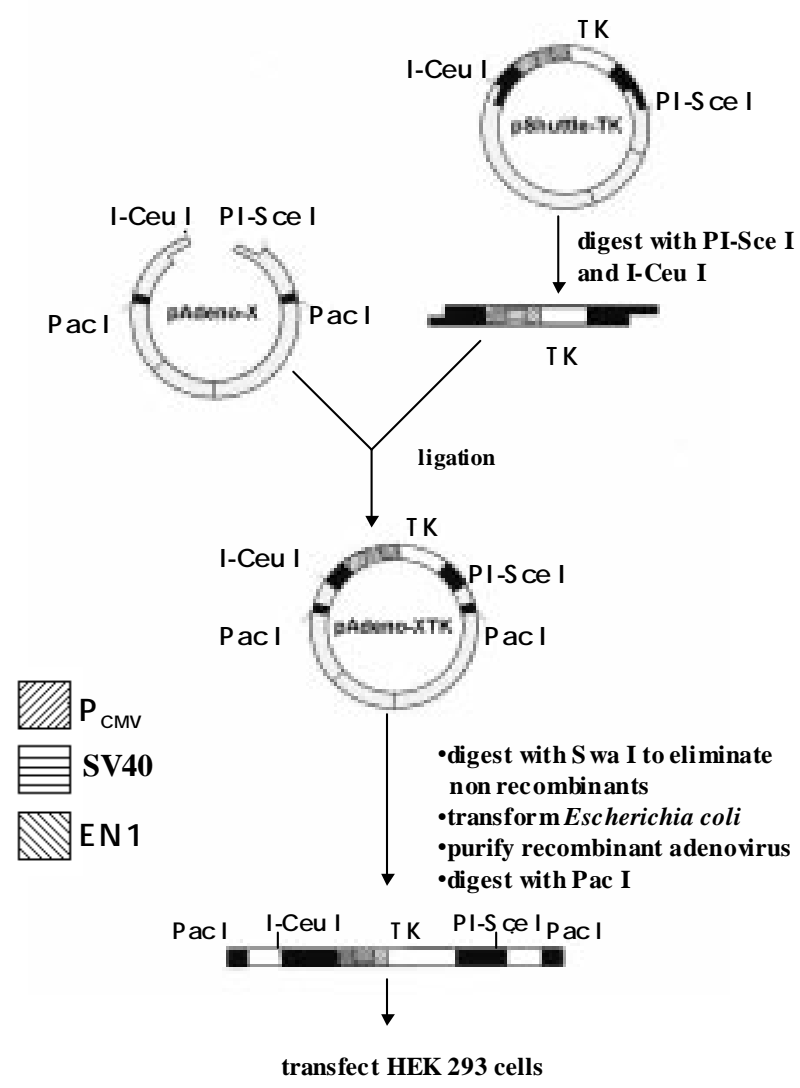

Fig. 1: schematic view of the construction of adenovirus carrying thymidine kinase gene using Adeno- $\mathrm{X}^{\mathrm{TM}}$ Expression System.
pShuttleTK recovery. The candidate clones were screened by digestion with appropriate restriction endonucleases. In our experience over $70 \%$ of the ampicilin resistant clones obtained carried the sought-after recombinant adenoviral plasmid.

Obtaining Ad-TK adenovirus in HEK293 cells - The plasmid pAdeno-XTK contains two PacI restriction sites, which are located at both ends of the viral genome, 3 ' and 5 ' of the inverted terminal repeats (ITRs). Thus, to ensure efficient replication and packaging of recombinant adenovirus carrying TK gene (Ad-TK), the plasmid was digested with PacI and used to transfect HEK 293 cells. When cells grew to confluence before viral plaques appeared, they were trypsinized and transferred to a larger flask, and after 21 days plaques appeared turbid due to light scattering by dead cells indicating the adenovirus presence. To confirm the presence of the TK gene in the recombinant adenovirus, the viral DNA was extracted and a Southern blot was carried out, using the DNA of recombinant adenovirus with the $\beta$-galactosidase gene (Ad- $\beta$ gal) as negative control and pShuttleTK as positive control. Fig. 2 shows the probe hybridized with viral DNA extracted from HEK 293 cells transfected with the Ad-TK construct.

Cytotoxicity of adenoviral vectors containing $T K$ gene in vitro - To determine whether recombinant adenovirus containing the three promoters $\left(\mathrm{P}_{\mathrm{CMV}}\right.$ IE, $\mathrm{SV} 40$ and EN1) upstream of TK gene would render tumor cells sensitive to ganciclovir-mediated cell killing, 40,000 HeLa cells were infected with either Ad- $\beta$ gal at 80,000 pfus or Ad-TK at different titers. The transduced cells were then supplied or not with GCV at $25 \mu \mathrm{g} / \mathrm{ml}$ in the culture medium. Four days later the cells infected with Ad- $\beta$ gal remained attached while the cells infected with Ad-TK detached completely from the plate at $60,000,30,000$ or 15,000 pfus. Cells infected with Ad-TK cultivated in the absence of GCV did not show evidence of cell killing (Fig. 3A). In a similar experiment, $40,000 \mathrm{CCR} 2$ cells infected with AdTK at 60,000 or 30,000 pfus and treated with GCV were completely killed. Lower virus titers $(15,000,7,500$ or 3,750 pfus) were not totally efficient. No toxic effect to the CCR2 cells was observed after infection with Ad-TK without GCV treatment (Fig. 3B).

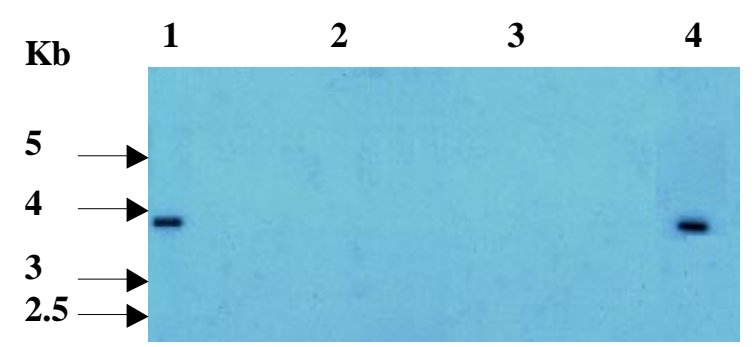

Fig. 2: Southern blot characterization of adenovirus carrying thymidine kinase gene (Ad-TK). Recombinant viral vectors were grown in HEK293 cells, purified, digested with Xba I and run in agarose gel. The resulting blot probed to detect TK gene is presented. Lanes - 1: $0.01 \mathrm{ng}$ of Ad-TK DNA; $2: 2 \mathrm{ng}$ of adenovirus carrying $\beta$ galactosidase gene (Ad- $\beta$ gal) DNA; $3: 4$ ng of Ad- $\beta$ gal DNA and 4: $0.001 \mathrm{ng}$ of pShuttle-TK plasmid digested with XbaI. The positions of molecular weight markers are indicated on the left. 

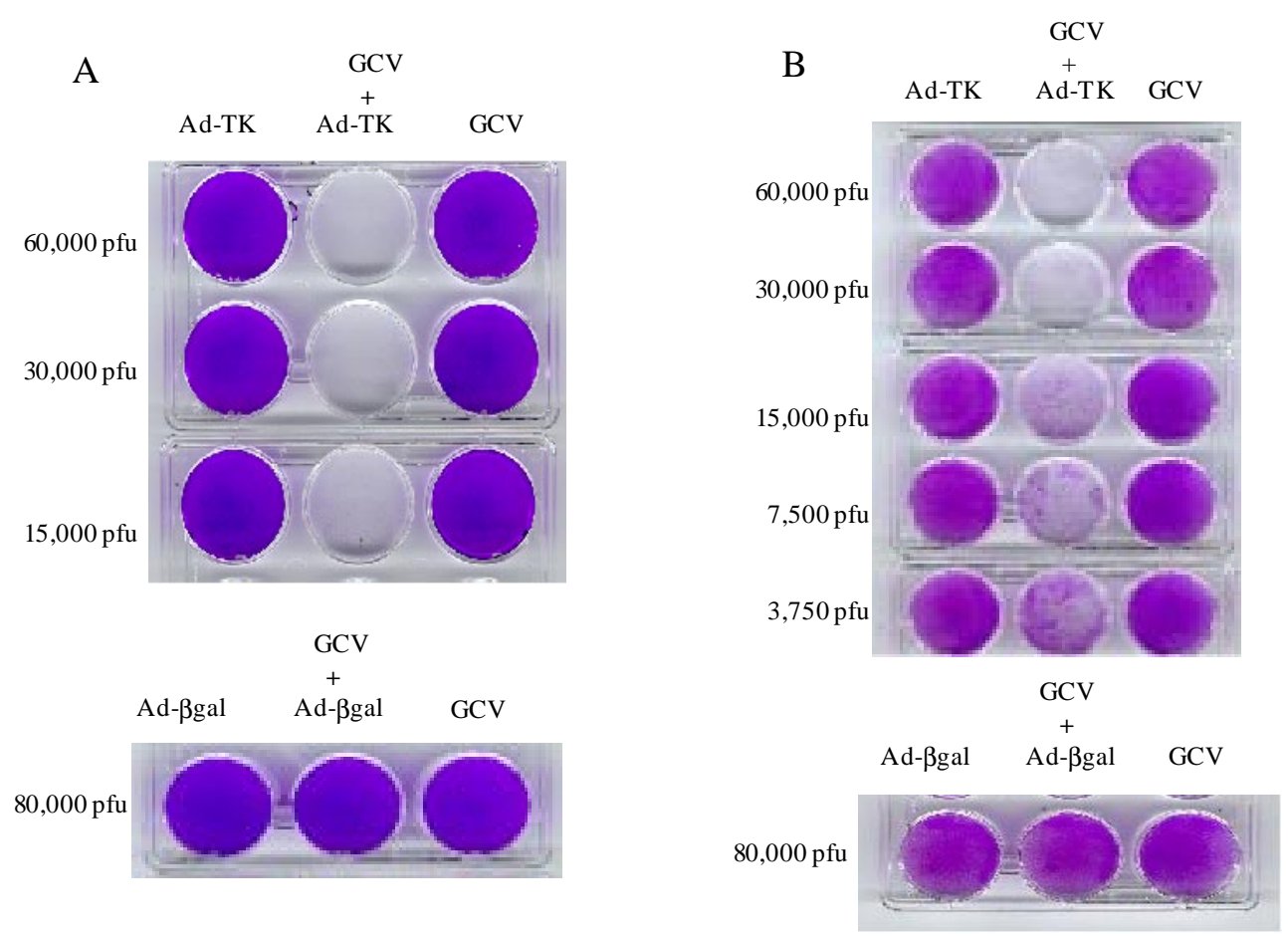

Fig. 3: infection of HeLa or CCR2 cells with adenovirus carrying thymidine kinase gene (Ad-TK). HeLa (A) or CCR2 (B) cells (40,000/ well), when indicated, were infected with Ad-TK (upper panels) or adenovirus carrying $\beta$-galactosidase gene (lower panels) with the indicated pfu number. Infected and uninfected (control) cells when indicated were treated with glanciclovir $(\mathrm{GCV})(25 \mu \mathrm{g} / \mathrm{ml})$. GCV treatment started $1 \mathrm{~h}$ after infection and the cells were fixed and stained 4 days later.

Analysis of TK gene expression in Ad-TK transduced cells - After transduction with Ad-TK, a northern blot analysis was done in RNA extracted from HeLa or CCR2 cells $48 \mathrm{~h}$ after transduction, to verify the size of the transcripts starting from any of the three promoters. We could detect two sizes of transcripts of TK gene, one derived from the close together $\mathrm{P}_{\mathrm{CMV} \mathrm{IE}} / \mathrm{SV} 40$ promoters and the other from the $1.5 \mathrm{~Kb}$ downstream EN1 promoter (Fig. 4). The relative amount of these transcripts was measured for each cell type in a PhosphorImager, and the ratio $\mathrm{P}_{\mathrm{CMV} \text { IE }}$ /SV40:EN1 was 3:2 for CCR2 and 4:1 for HeLa cells.

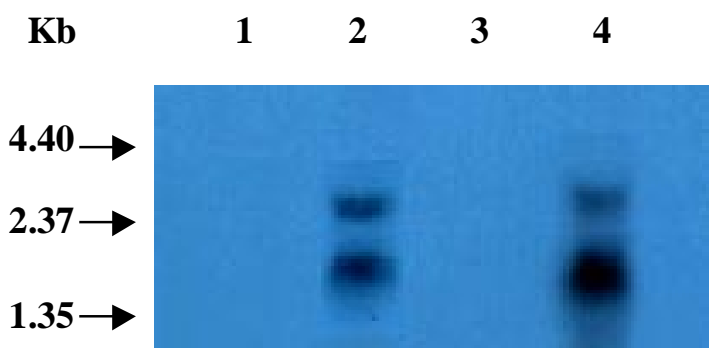

Fig. 4: Northern analysis of thymidine kinase (TK) gene expression in adenovirus carrying thymidine kinase gene (Ad-TK) transduced cells. RNA was extracted from HeLa or CCR2 cells $48 \mathrm{~h}$ after transduction with Ad-TK. The resulting blot probed to detect TK gene transcripts is presented. Lanes - 1: untransduced CCR2 cells; 2: transduced CCR2 cells; 3: untransduced HeLa cells; 4: transduced HeLa cells. The positions of molecular weight markers are indicated on the left.

\section{DISCUSSION}

Conventional methods for creating recombinant adenovirus vectors rely on in vitro homologous recombination in HEK 293 cells or $E$. coli. We did experiments with pJM17 and p $\Delta$ E1sp1A (Bett et al. 1994) and the pAdEasy system (He et al. 1998) but in our hands they were inefficient. The protocol originally developed by Mizuguchi and Kay $(1998,1999)$ gave us straightforward results. The procedure is based on the application of an in vitro ligation to incorporate the gene of interest into a plasmid containing replication-incompetent human adenoviral type 5 genome (pAdeno-X). This system provides a mean to obtain a homogeneous population of recombinant adenovirus, which avoids the need of plaque purification procedures.

In the experiments reported here, we first tested if the TK gene sub-cloned in the vector pSHTK was functional. That was accomplished by the transfection of CCR2 cells that showed sensitivity to GCV treatment. Using the TK gene expression cassete from pSHTK, Ad-TK was constructed and $\mathrm{P}_{\mathrm{CMV}}$ IE added upstream of the two previous promoters (Fig. 1). From the results shown in Fig. 3, we conclude that the presence of the three promoters $\left(\mathrm{P}_{\mathrm{CMV} \mathrm{IE}}, \mathrm{SV} 40\right.$ and EN1) resulted in efficient expression of TK gene from the Ad-TK virus. Furthermore, in spite of using a number of pfus smaller $(30,000)$ than the number of cells $(40,000)$, there was complete elimination of CCR2 cells (Fig. 3B). In the experiment using the same number of HeLa cells, complete elimination occurred at 30,000 and 
15,000 pfus (Fig. 3A). This phenomenon has been termed the bystander effect (Culver et al. 1992, Freeman et al. 1993), where GCV kills cells expressing TK gene and nearby cells that are not expressing it. Previous studies (Fick et al. 1995, Mesnil et al. 1996) have shown that gap junctions play a role in the bystander effect of the TK/GCV system, by allowing the passage of phosphorylated GCV metabolites from $\mathrm{TK}^{+}$to $\mathrm{TK}^{-}$cells. This is of key importance in the treatment of solid tumors in vivo, were an injection of Ad-TK into the center of the cell mass resulted in the regression of the whole tumor (Eastham et al. 1996).

In Fig. 4 is shown that the Ad-TK transduced cells have two sizes of transcripts for TK gene, one derived from the close together $\mathrm{P}_{\mathrm{CMV} \text { IE }} / \mathrm{SV} 40$ promoters and the other from the $1.5 \mathrm{~Kb}$ downstream EN1 promoter. The ratios of transcription indicate a differential expression in the target cells since the ratio $\mathrm{P}_{\mathrm{CMV} I E} / \mathrm{SV} 40: \mathrm{EN} 1$ was $3: 2$ for CCR2 and 4:1 for HeLa cells. Suicide gene employed in cancer gene therapy requires expression from promoters that can be efficient in different cell types, and as it has been reported different cell types affect the efficiency of a given promoter activity (Everett 1988, Shillitoe \& Noonan 2000). This may cause important differences in the levels and duration of the suicide gene expression and lead to a failure of efficiency of one promoter in a given tumor cell. This failure is less likely to occur with the Ad-TK described here due to the presence of three strong promoters, in such a way that when one promoter is weak the others may be more effective, thus optimizing this system and having the potential to be effective in a large variety of tumor cells.

\section{REFERENCES}

Anderson LM, Swaminathan S, Zackon I, Tajuddin AK, Thimmapaya B 1999. Adenovirus-mediated tissue-targeted expression of HSVtk gene for the treatment of breast cancer. Gene Therapy 6: 854-864.

Berkner KL 1992. Expression of heterologous sequences in adenoviral vectors. Curr Top Microbiol Immunol 158: 3966.

Bett AJ, Haddara W, Prevec L, Graham FL 1994. An efficient and flexible system for construction of adenovirus vectors with insertions or deletions in early regions 1 and 3. Proc Natl Acad Sci USA 91: 8802-8806.

Chen S, Shine HD, Goodman JC, Grossman RG, Woo SLC 1994. Gene therapy for brain tumors: regression of experimental gliomas by adenovirus-mediated gene transfer in vivo. Proc Natl Acad Sci USA 91: 3054-3057.

Chomczynski P, Sacchi N 1987. Single step method of RNA isolation by acid guanidinium thiocyanate-phenol-cloroform extraction. Anal Biochem 162: 156-159.

Culver KW, Ram Z, Walbridge S, Ishii H, Oldfield EH, Balese, RM 1992. In vivo gene transfer with retroviral vector producer cells for treatment of experimental brain tumors. Science 256: 1550-1552.

Eastham JA, Chen SH, Sehgal I, Yang G, Timme TL, Hall SJ, Woo SL, Thompson TC 1996 Prostate cancer gene therapy: herpes simplex virus thymidine kinase gene transduction followed by ganciclovir in mouse and human prostate cancer models. Human Gene Therapy 7: 515-523.

Ellion GB, Furman PA, Fyfe JA, DeMiranda P, Beauchamp L, Schaeffer HJ 1977. Selectivity of action of an antiherpetic agent, 9-(2-hydroxyethoxymethyl) guanine. Proc Natl Acad Sci USA 74: 5716-5720.

Everett RD 1988. Promoter sequence and cell type can dramatically affect the efficiency of transcriptional activation induced by herpes simplex virus type 1 and its immediateearly gene products. J Mol Biol 203: 739-751.

Ezzeddine ZD, Martuza RL, Platika D, Short MP, Malick A, Choi B, Breakefield XO 1991. Selective killing of glioma cells in culture and in vivo by retrovirus tranfer of the herpes simplex virus thymidine kinase gene. New Biol 3: 608614.

Fick J, Barker FG, Dazin P, Westphale EM, Beyer EC, Israel MA 1995. The extent of heterocellular communication mediated by gap junctions is predictive of bystander tumor cytotoxicity in vitro. Proc Natl Acad Sci USA 24: 1107111075.

Freeman SM, Whartnby KA, Koeplin DS, Moolten FL, Abboud CN, Abraham GN 1993 The "bystander effect": tumor regression when a fraction of the tumor mass is genetically modified. Cancer Res 53: 5274-5283.

Graham FL, Smiley J, Russel WC, Nairn R 1977. Characteristics of a human cell line transformed by DNA from a human adenovirus type 5. J Gen Virol 36: 59-72.

He TC, Zhous S, Da Costa LT, Yu J, Kinzler KW, Volgelstein B 1998. A simplified system for generating recombinant adenoviruses. Proc Natl Acad Sci USA 95: 2509-2514.

Herman JR, Alder HL, Aguilar-Cordova E, Rojas-Martinez A, Woo S, Timme TL, Wheeler TM, Thompson TC, Scardino PT 1999. In situ gene therapy for adenocarcinoma of the prostate: a phase I clinical trial. Hum Gene Ther 97: 10831092.

Hitt M, Bett A J, Addison C L, Prevec L, Graham F L 1998. Construction and propagation of human adenovirus vectors. In JE Celis, Cell Biology: A Laboratory Handbook, Academic Press, San Diego, p. 500-512.

Jasiulionis MG, Chammas R, Ventura AM, Travassos LR, Brentani RR 1996. Alpha6-beta1 Integrin, a major cell surface carrier of beta1-6-branched oligosaccharides, mediates migration of Ej-ras-transformed fibroblasts on laminin-1 independently of its glycosylation state. Cancer Res 56: 1682-1689.

Mansour SL, Thomas KR, Capecchi, MR 1988. Disruption of the proto-oncogene int- 2 in mouse embryo-derived stem cells: a general strategy for targeting mutations to non-selected genes. Nature 336: 348-352.

McKnight SL 1980. The nucleotide sequence and transcript map of the herpes simplex virus thymidine kinase gene. Nucleic Acids Res 8: 5949-5964.

Mesnil M, Piccoli C, Tiraby G, Willecke K, Yamasaki H 1996. Bystander killing of cancer cells by herpes simplex virus thymidine kinase gene is mediated by connexins. Proc Natl Acad Sci USA 5: 1831-1835.

Mizuguchi H, Kay MA 1998. Efficient construction of a recombinant adenovirus vector by an improved in vitro ligation method. Hum Gene Ther 9: 2577-2583.

Mizuguchi H, Kay MA 1999. A simple method for constructing E1- and E1/E4-deleted recombinant adenoviral vectors. Hum Gene Ther 10: 2013-2017.

Moolten F 1986. Tumor chemosensitivity conferred by inserted herpes thymidine kinase genes: paradigm for a prospective cancer control strategy. Cancer Res 46: 5276-5281.

Park JY, Elshami AA, Amin K, Rizk N, Kaiser LR, Albelda SM 1997. Retinoids augment the bystander effect in vitro and in vivo in herpes simplex virus thymidine kinase/ganciclovir - mediated gene therapy. Gene Ther 4: 909-917.

Rosenfeld ME, Feng M, Michel SI, Siegal GP, Alvarez RD, Curiel DT 1995. Adenoviral-mediated delivery of the her- 
pes simplex virus thymidine kinase gene selectively sensitizes human ovarian carcinoma cells to ganciclovir. Clin Cancer Res 1: 1571-1580.

Sambrook J, Fritsch EF, Maniatis T 1989. Molecular Cloning: a Laboratory Manual, 2nd ed., Cold Spring Harbor Laboratory Press, Cold Spring Harbor, NY.

Samejima Y, Meruelo D 1995. "Bystander killing” induces apoptosis and is inhibited by forskolin. Gene Ther 2: 5058.

Shillitoe EJ, Noonan S 2000. Strength and specificity of different gene promoters in oral cancer cells. Oral Oncol 36: 214-220.

Sterman DH, Treat J, Litzky LA, Amin KM, Coonrod L, Molnar-Kimber K, Recio A, Knox L, Wilson JM, Albelda SM, Kaiser KR 1998. Adenovirus-mediated herpes simplex virus thymidine kinase/ganciclovir gene therapy in patients with localized malignancy: results of phase I clinical trial in malignant mesothelioma. Hum Gene Ther 97: 10831092.
Su H, Lu R, Chang JC, Kan YW 1997. Tissue-specific expression of herpes simplex virus thymidine kinase gene delivered by adeno-associated virus inhibits the growth of human hepatocellular carcinoma in athymic mice. Proc Natl Acad Sci USA 94: 13891-13896.

Trask TW, Trask RP, Cordova EA, Shine HD, Wyde PR, Goodman JC, Hamilton WJ, Martinez AR, Chen SH, Woo SLC, Grossman RG 2000. Phase I study of adenoviral delivery of HSV-tk gene and ganciclovir administration in patients with recurrent malignant brain tumors. Mol Ther 1: 195-203.

Ventura AM, Arens MQ, Srinivasan A, Chinnadurai G 1990. Silencing of human immunodeficiency virus long terminal repeat expression by an adenovirus E1 a mutant. Proc Natl Acad Sci USA 87: 1310-1314.

Ventura AM, Villa LL 1993. Plasmid pSH: a strong mammalian expression vector. Biochem Biophys Res Comun 192: 867869. 